\title{
A MEMS/MICROSYSTEM CURRICULUM WITH INTERNATIONAL DISSEMINATION
}

\author{
L. C. McAfee, K. Najafi, Y.B. Gianchandani, K. D. Wise, and M. M. Maharbiz \\ Engineering Research Center for Wireless Integrated MicroSystems \\ Electrical Engineering \& Computer Science Department, The University of Michigan \\ Ann Arbor, MI 48109-2101, UNITED STATES
}

\author{
D.M. Aslam \\ Engineering Research Center for Wireless Integrated MicroSystems \\ Electrical and Computer Engineering Department, Michigan State University \\ East Lansing, MI, 48824, UNITED STATES
}

P.L. Bergstrom, C.R. Friedrich

Engineering Research Center for Wireless Integrated MicroSystems

Electrical Engineering Dept and Mechanical Engineering Dept, Michigan Technological University

Houghton, MI 49931, UNITED STATES

\begin{abstract}
The Engineering Research Center for Wireless Integrated MicroSystems has developed five core courses that provide a broad comprehensive curriculum in MEMS and microsystems for upper-level undergraduate students, graduate students, and industry professionals. The curriculum design has flexibility that invites development of other core courses, as well as related technical electives and breadth electives. The core courses provide instruction in MEMS, microsystems, laboratory measurements, societal impact, and a major design experience. The course enrollments have been high. The existence of this core curriculum has also led to the establishment of a Master of Engineering degree in Integrated Microsystems; thus, industry professionals have a focused set of coursework, while flexibility permits custom tailoring of the total course package to serve individual preferences. Distance education dissemination of the courses as whole courses, or as discrete portions of course materials, is available. The core courses originate at the University of Michigan and have been distributed to Michigan State University, Michigan Technological University, Howard University, University of Puerto Rico - Mayaguez, and Western Michigan University. Rochester Institute of Technology has used course materials from the core courses in its offerings. Other institutions that have used the course web-streaming video and course materials are University of Lille, Darmstadt University, and Middle East Technical University.

This paper has descriptions about the curriculum design process across the three partnering universities, resources for (and development of) individual course materials, development of primary and secondary instructors, as well as the responsibilities and preparation of local instructors at the receiving institutions (universities and industry). Also, alternative methods for MEMSbased distance education at a reasonable cost are described.
\end{abstract}

\section{INTRODUCTION}

The Engineering Research Center (ERC) for Wireless Integrated MicroSystems (WIMS) has developed five core courses (Figure 1) that provide a broad comprehensive curriculum in MEMS and microsystems for upper-level undergraduate students, graduate students, and industry professionals. The five core courses originate at the University of Michigan (UM): Introduction to MEMS (EECS 414), Integrated Microsystems Laboratory (EECS 425), Advanced MEMS Devices and Technologies (EECS 514), Advanced Integrated Microsystems (EECS 515), and Societal Impact of Microsystems (EECS 830). The first of these courses has now been disseminated worldwide, while the second is exploring ways of porting a laboratory course to different universities. The Societal Impact course explores the global societal challenges that will be faced by students during their careers and how microsystems will be used to address them. Each course is a four credit-hour course; however, EECS 830 is a two credit-hour course.

During a two-day WIMS education retreat that was well attended by faculty members of the three core-partner universities, the WIMS MEMS/microsystem curriculum was designed to (1) provide students with a comprehensive background in fabrication, MEMS/microsystems theory, practice, applications, and technology, (2) accommodate students from broad disciplines across science and engineering by developing a first course that had minimal prerequisites in science (physics and chemistry), math, and engineering, (3) use the first course as the only prerequisite for the remaining core courses, (4) develop course materials with the expectation that distance education with webbased dissemination would be a primary format, (5) serve undergraduate and graduate students, as well as serve practicing professionals, (6) be available for students at all three partnering universities (UM, MSU, MTU), (7) develop skills in critical assessment of diverse technologies and devices, (8) develop engineering project management skills, (9) be a core set of requirements for a graduate professional degree program to accommodate practicing professionals desiring an advanced degree, and (10) be flexible enough to encourage creation of other courses with links to broad interdisciplinary areas. All of these design goals have been met (and in many cases exceeded), with high student enrollment in all the core courses at WIMS ERC partnering universities. Several of the courses have been adopted by other universities, nationally and internationally. Curriculum approvals and local course numbers have been obtained at Michigan State University (MSU) and Michigan Technological University (MTU). Also, these courses have been used at Western Michigan University (WMU), University of Puerto Rico - Mayaguez (UPRM), Howard University (HU), and Rochester 
Institute of Technology (RIT) in the United States, and internationally at the University of Lille, Darmstadt University, and Middle East Technical University.

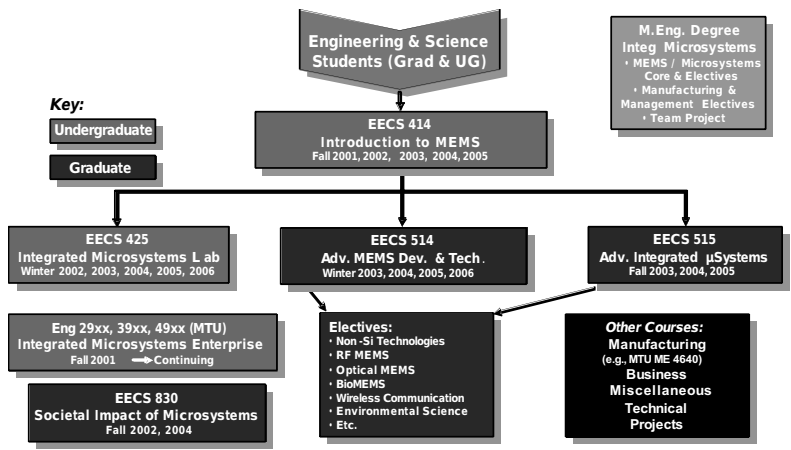

Figure 1. WIMS ERC MEMS and Microsystems Curriculum Design.

In addition, technical electives offered include Integrated Analog/Digital Interface Circuits (EECS 511), RF Wireless MEMS (EECS 598A), and BioMEMS Through the Developing Organism (EECS 598B). These courses have led to the inclusion of MEMS and microsystem topics in other courses as well, from sophomore year to the advanced graduate level.

The following segments of this paper describe ways that the goals were addressed and have progressed. Issues associated with development of each course from EECS 414 to EECS 830 are presented in this paper. Enrollment in each course is presented in a table including all courses. Factors are presented associated with distance education and a master of engineering degree program. A list of acronyms is at the end of this paper.

\section{INTRODUCTION TO MEMS (EECS 414)}

One of the main challenges in MEMS education has been teaching the first course to novice undergraduate students. Several questions immediately arise as one begins to prepare such a course. Who is taking the course and what backgrounds do they have? What should be the prerequisites, if any? Should the first course be available to most engineering students, or should access be limited by adding one or several prerequisites? When is the right time to take this course? What should be taught in the course, what should be the balance between theory and practice/technology, and what is the objective of the course? Should it have a lab component, should it have a major design project, or should it have several projects? Should design and software tools be taught? If the course is available to both undergraduate and graduate students, how can they be accommodated in a single course, or should they be? What does/would industry like to see in this course? Is one course sufficient to prepare students for practicing MEMS in industry? Undoubtedly many institutions have faced these and other questions as they attempted to prepare such a course. A few answers/decisions for these questions are presented here, along with the philosophy and experience gathered at the University of Michigan over the past five years since we started teaching an "Introduction to MEMS" course.

We believe that the first course should be open to all engineering and science students with an interest in learning about MEMS, irrespective of their discipline. The only requirements are basic math, physics, chemistry, and a basic background in electrical and mechanical physics as is typically offered in most engineering/science curricula. This introductory course is designed for students who are not familiar with MEMS, microfabrication and micromachining technologies, integrated circuits, or non-electrical devices and systems. The course has discussion sections that enhance both mechanical and electrical background areas for science majors (such as physics and chemistry majors, etc.) and other engineering majors (such as non-EE and non-ME) students. The course has also been taken via the internet by students at several other institutions, and challenges in this area have been identified.

Since micromachining technology affects all aspects of MEMS, the course starts with a detailed coverage of microfabrication and micromachining, including planar thin-film processes, photolithographic techniques, deposition and etching techniques, wafer bonding, and electroplating. These topics are followed by a detailed coverage of surface, bulk, and electroplating micromachining technologies and review of example devices. A designer of MEMS requires knowledge and expertise across several different disciplines. Therefore, this course pays special attention to teaching of fundamentals of transduction mechanisms (i.e. conversion of non-electronic signals to electronic signals), including capacitive, piezoresistive, and thermal techniques, and design and analysis of micromachined sensors and actuators. The course also introduces students to MEMS-specific computer-aided design (CAD) simulators, including Coventorware and ANSYS. Assignments allow students to use CAD tools to simulate a few sample structures and compare their operation to calculated values.

Figure 2 summarizes the topics covered in EECS 414 (highlighted in bold) in the context of all topics that we think eventually should be covered in an effective MEMS curriculum. The first course Introduction to MEMS (EECS 414) is the only prerequisite needed for follow-on courses. During its first offering in Fall Term 2001, a textbook Microsystem Design [1] was designated. After that term, the reading materials resources have been course notes and PowerPoint slides that were developed by UM faculty, as well as numerous designated journal and conference articles [2-4]; these resources better match the content and flow of the course. These resources have been readily shared and provided to others who seek to develop a course at their institution.

\begin{tabular}{|c|c|c|}
\hline Materials/Fabrication & $\underline{\text { Transducers }}$ & Microsystems \\
\hline Materials & Energy Domains & Circuits \\
\hline Silicon \& Related & Electrical & Sensor \& Actuator \\
\hline Semiconductors & Mechanical & $A-D$ Conversion \\
\hline Non-Silicon & Thermal & \\
\hline Micro-Fabrication & Chemical/Gas/Bio & System \\
\hline Photolithography & Optical/Radiative & Architecture, \\
\hline Planar & & Partitioning \\
\hline Microfabrication & Transduction & Signal Processing \\
\hline Micromachining & Techniques & Power Issues \\
\hline Photolithographic & Capacitive & Power/Energy \\
\hline (Parallel) & Piezoresistive & Source \\
\hline --- Planar & Thermal & Power Dissipation \\
\hline --- Si Etching \& & Magnetic & Management \\
\hline Machining & Piezoelectric & Noise and Signals \\
\hline Non-Photographic & Resonant & Sources \\
\hline (Serial) & Tunneling & Limits \\
\hline --- Non-planar, 3D & Optical/Radiative & Communication \\
\hline --- Standard & Others & Testing \& Calibration \\
\hline Precision & Sensors & Integration \\
\hline Machining & Actuators & Packaging \\
\hline ld - & $\begin{array}{l}\text { LEGEND: } \\
\text { troduction to MEMS (1 }\end{array}$ & 414) \\
\hline Plain --- Advance & IEMS Devices and Techn & ggies (EECS 514) \\
\hline
\end{tabular}

Figure 2. Content Topics for Three Core Courses.

Table 1 shows the enrollment in the course (at all institutions), including the breakdown of undergraduate and graduate students taking the course at the University of Michigan for the past five years. Although the initial enrollments in the course were mostly graduate students, it now has a 2:1 ratio of 
undergrads to grads. This trend clearly indicates the growing interest in MEMS as a discipline often required by industry.

\begin{tabular}{|l|c|c|c|c|c|}
\hline \multicolumn{7}{|c|}{$\begin{array}{l}\text { Table 1. Enrollment History by Groups in } \\
\text { Introduction to MEMS (EECS 414) }\end{array}$} \\
\hline & 2001 & 2002 & 2003 & 2004 & 2005 \\
\hline UM Ugrad Students & 20 & 26 & 61 & 52 & 57 \\
\hline UM Grad Students & 37 & 40 & 43 & 25 & 26 \\
\hline UM Total Students & $\mathbf{5 7}$ & $\mathbf{6 6}$ & $\mathbf{1 0 4}$ & $\mathbf{7 7}$ & $\mathbf{8 3}$ \\
\hline University Dis.Ed. Stds & 25 & 23 & 42 & 45 & 48 \\
\hline US Total Students & 82 & 89 & 146 & 122 & 131 \\
\hline Industry Dis.Ed. Stds & & & 3 & 5 & 3 \\
\hline International Dis.Ed.Stds & & 29 & 20 & 31 & 64 \\
\hline \hline Total StudentsWorldwide & $\mathbf{8 2}$ & $\mathbf{1 1 8}$ & $\mathbf{1 6 6}$ & $\mathbf{1 5 8}$ & $\mathbf{1 9 8}$ \\
\hline
\end{tabular}

\section{INTEGRATED MICROSYSTEMS LABORATORY (EECS 425)}

In this one-semester laboratory course, students work in four-person teams; they define, design, fabricate, and test a microsystem of their choice. The microsystems realized typically consist of a two-chip combo: a transducer chip and a circuit chip, fabricated over the course of a 14-week semester (six weeks in microsystem design, five weeks in fabrication, and three weeks in test). The course accepts senior and first-year graduate students from either a device or circuit or MEMS background and serves as a major design experience for undergraduates. It allows students to understand the interactions among design, fabrication, and test, and for many this course is the only chance they will ever have to take a chip all the way from inception to final test. Students come from various

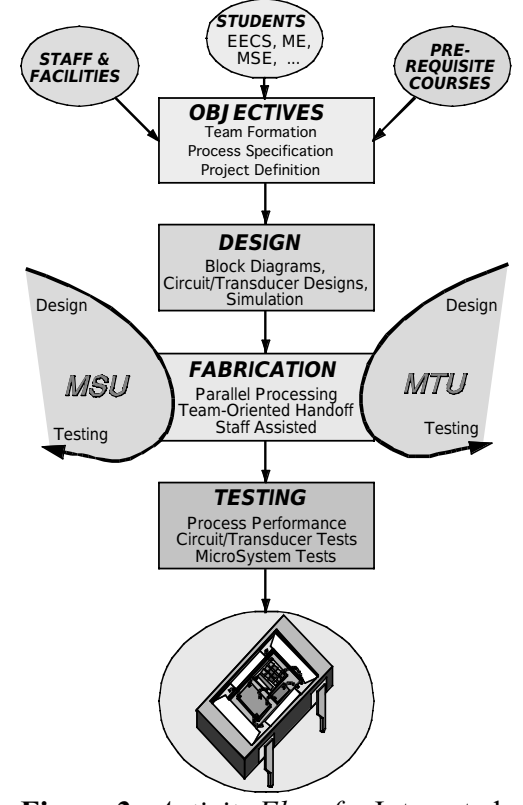

Figure 3. Activity Flow for Integrated Microsystems Laboratory (EECS 425). engineering majors (electrical, mechanical, biomedical, and chemical), as well as from physics.

Figure 3 shows the activity flow for the course, consisting of two 80-minute lectures per week plus one 3-hour laboratory session. The lectures are taped and available over the web, permitting the course to be taken at other universities (currently Michigan State and Michigan Tech) with an on-site instructor. Designs created by students at MSU and MTU are fabricated at UM (during those fabrication weeks, MSU and MTU students fabricate other devices in their own laboratories) and are then returned to them for testing. For the circuitry, a five-mask ionimplanted silicon-gate LOCOS E/D NMOS process is used. While this process lacks the performance of a full CMOS process, it can be run in five weeks or less and exposes students to a full range of process steps. For the transducers, a silicon-on-glass (dissolved-wafer) process is used, allowing a wide range of devices to be realized in six masks and allowing wafer bonding and diffused etch-stops to be illustrated. The students are given the processes and a $2 \mathrm{~mm} \times 2 \mathrm{~mm}$ die area for each chip and are challenged to get the best performance they can from whatever design they elect to realize.

Figure 4 shows a die photograph and close-up of a typical transducer die, while Figure 5 shows one of the circuits realized in the course along with one team in cleanroom garb. Mask fabrication and ion implantation are done in foundries, with students performing all other

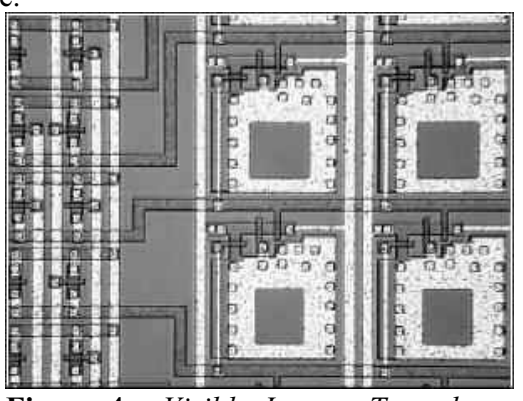

Figure 4. Visible Imager Transducer Die for Integrated Microsystems Laboratory (EECS 425). processing steps, except for those processes involving chemical vapor deposition that are done by engineering staff. Visible imagers, pressure sensors, accelerometers, g-switches, tactile imagers, micro-flowmeters, micro-mirror arrays, mass sensors, and Pirani gauges have been realized. The course projects often find their way into student resumes and occasionally receive broader exposure. A project two years ago won second place in the Design Automation Conference (DAC) student design contest and was featured there and at the International Solid-State Circuits Conference.
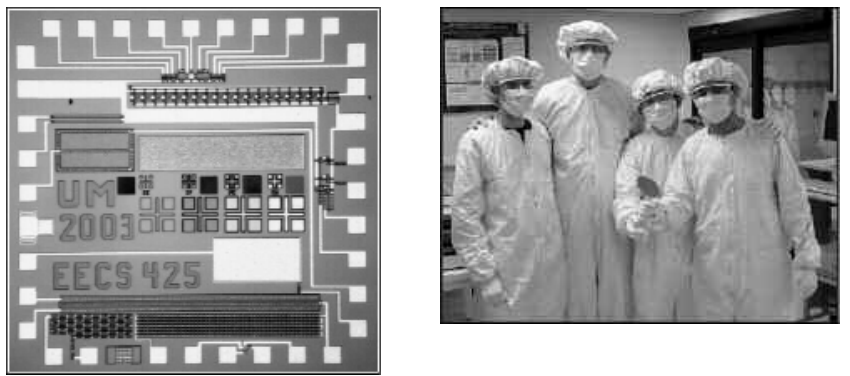

Figure 5. An IC produced in the Integrated Microsystems Laboratory (EECS 425) and a photo of students in the cleanroom.

\section{ADVANCED MEMS DEVICES AND TECHNOLOGIES (EECS 514)}

EECS 514 is largely an Advanced MEMS Technologies course as it continues the MEMS topics started in EECS 414, as indicated in the Figure 2 list of topics. EECS 514 covers advanced topics dealing with MEMS technologies, transduction mechanisms, and microfabricated sensors and actuators. Many emerging micromachining technologies, such as laser and electrodischarge micromachining, and non-conventional materials, such as silicon-carbide and diamond are discussed. Transduction techniques, including electromagnetic, piezoelectric, resonant, tunneling, and others are presented.

The course reviews different types of sensors for measurement of physical parameters such as acceleration, rotation rate, and pressure, as well as chemical and gaseous parameters for gas and chemical sensing applications. It also reviews different micro-actuation techniques and their application in MEMS. The course also reviews MEMS for use in microfluidics and in biomedical applications. An important part of this course is a design project carried out in teams who develop, simulate, and 
design a device of their choice, and present their findings in a technical article. MEMS-specific CAD tools such as Coventorware and ANSYS are used to design and model the devices. The course is highly structured, with two intermediate presentations and a final one at the end of the course. Typically, students read 25 to 40 papers [5-7], and 6 to 8 student reports. A highlight assignment is students working in teams to develop sensor or actuator concept MEMS; see Figure 6 for a sample of three concept projects. The concept of an NSF-style panel discussion and peer review procedure is discussed. (However, the reports are not written in proposal style, and the students are not expected to project beyond their findings to propose work that will be done in the future. That approach comes up in EECS 515.) All students provide individual assessments of all projects at the end of the course. Students have been from several engineering majors: electrical, mechanical, biomedical, and chemical engineering, as well as from applied physics. All course materials, including lecture notes and lecture videos, are available via the web.
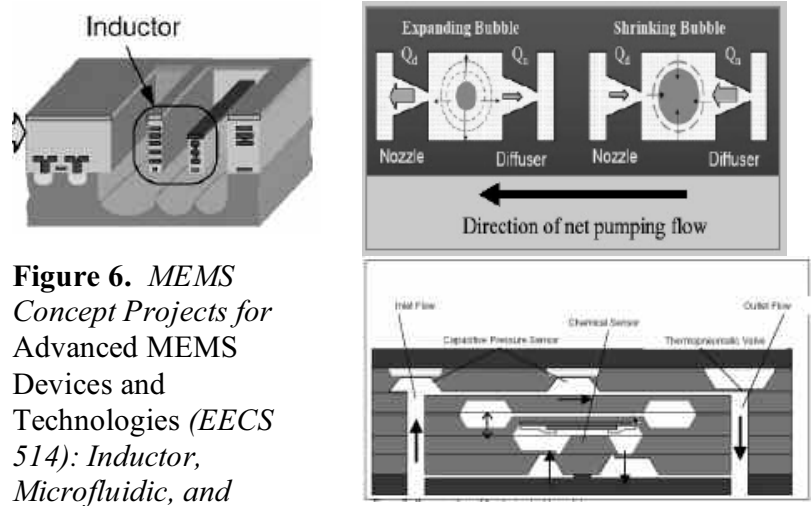

Figure 6. MEMS Concept Projects for Advanced MEMS

Devices and

Technologies (EECS

514): Inductor,

Microfluidic, and

Integrated Sensors

Devices.

\section{ADVANCED INTEGRATED MICROSYSTEMS (EECS 515)}

EECS 515 is an Advanced Integrated Microsystems course, building upon the MEMS topics and microsystems introduction presented in EECS 414. Prerequisites for this course include the equivalent of EECS 414 or EECS 514, and graduate standing. The students are also expected to have a working knowledge of basic analog circuits. It is desired that students would have completed EECS 425, but not required. EECS 515 is the third in the 414, 514,515 trio of courses that was developed as part of the MEMS/Microsystems core curriculum (with topics identified in Figure 2). As such, it is directed primarily at graduate students and industry professionals who have already achieved a level of comfort with MEMS technology, and are familiar with the important transduction methods, device concepts, and fabrication techniques. As in EECS 514, students read 25 to 40 papers [5-7], and 6 to 8 student reports. For EECS 515, a highlight assignment is students doing an NSF-style proposal centered around a microsystem design to solve an application; see Figure 7 for a microsystem design template, and a diagram for a cardiac stent microsystem project.

The topics covered in this course are a mix of device and circuit issues that are closely inter-related and are critical to a full understanding of microsystems. They include, for example, general ways to analyze noise in electronics and sensors; various kinds of interface circuits for capacitive, resistive, tunneling and other kinds of sensors; proportional integral controllers; dithering and modulating circuits; switched-capacitor interface circuits; correlated double-sampling; calibration schemes; system organization; digital bus protocols for transducer systems; packaging; and cost projections. The topics are relevant to both industrial practice and microsystems research, and address both fundamental and practical problems that arise in this field of engineering. An important part of this course is the team project, which requires students to develop research proposals that are then reviewed by the class in NSF-style panels, using both technical merit and broader impact as evaluation criteria. The EECS 515 project bears similarity to the project in EECS 514, but with important differences. a) The project report is written proposal-style, so the work performed during of the semester is intended to provide convincing preliminary results for the proposal. The students are encouraged to think of the strategic end goals, and determine the best minimum set of calculations, simulations, and analysis to address them. b) The proposals are required to include systems aspects, and thus must cover a circuit in addition to a sensor or actuator. c) Budgeting and milestone planning for the proposed work are required. Students have been from several engineering majors: electrical, mechanical, biomedical, and chemical engineering, as well as from applied physics. This course is available to distance education students via the web.

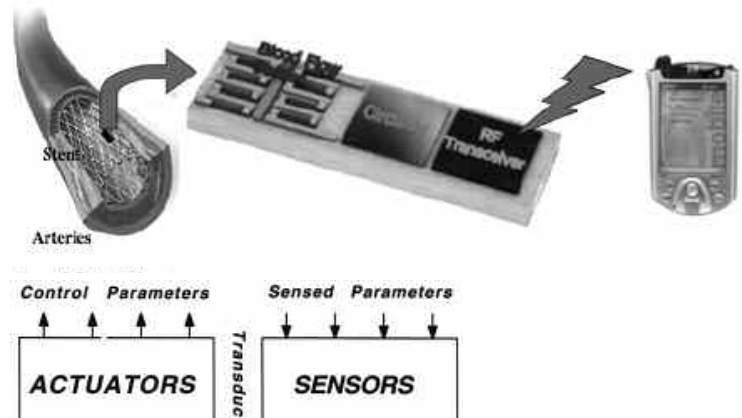

Figure 7.

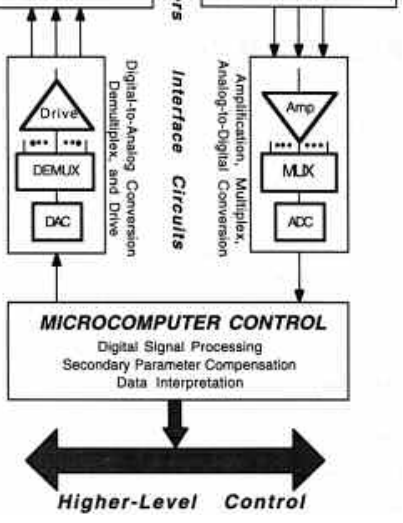

Microsystem

Design Template and Cardiac Stent Microsystem Project for Advanced Integrated Microsystems (EECS 515).

\section{SOCIETAL IMPACT OF MICROSYSTEMS (EECS 830)}

During the next two decades, microsystems are expected to have a pervasive impact on society as they are used to couple electronics to the non-electronic world. Microsystems will be used to monitor our environment (global warming, pollution, improved weather forecasting), provide homeland security, improve transportation systems (vehicles and infrastructure), and spark dramatic progress in health care (genetics, proteomics, wearable and implantable microsystems for diagnostic and therapeutic use). This course explores the societal challenges that will be faced by our present engineering students during their careers and how microsystems can be used to address them. As a two credit-hour course, the class meets once per week in a two 
hour session; the basic format is an hour-long (invited) seminar presentation followed by an hour of questions and discussion.

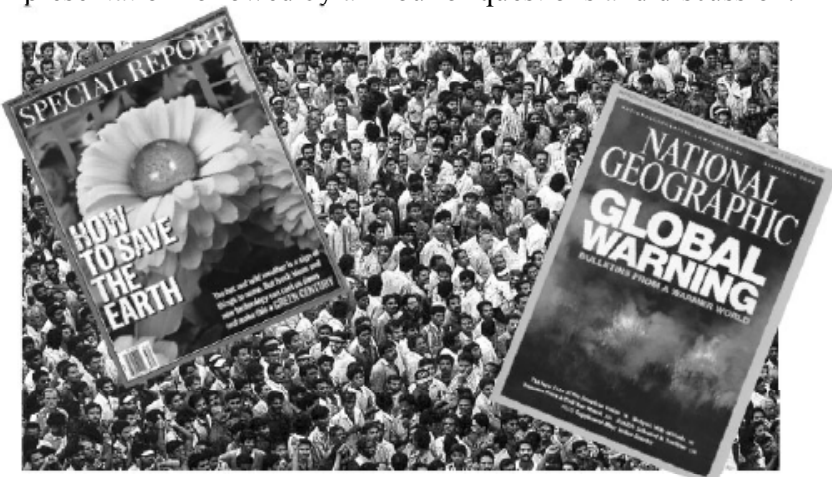

Figure 8. The Societal Impact of Microsystems course examines coming societal challenges and ways that microsystems will help address them. The course includes a component of engineering ethics, explores the origins of innovation, and considers the pioneering developments that have led us to where we are .

Seminar speakers have included former astronauts, experts on transportation and global warming, and industrial and governmental leaders in the area of health care. Topics have included clean air, clean water, homeland security, manufacturing, global warming, population growth and its implications, nanotechnology, space exploration, and medical implants, as well as engineering ethics. Students have regular homework assignments and select a topic of interest to them on which to do a term report. These oral reports have been very successful in allowing fascinating looks at many additional topics. In addition to societal challenges, the course also offers the opportunity to examine pioneers in electronics, from Benjamin Franklin to Robert Noyce, to obtain insight into the origins of innovation and the challenges faced in the past. Figure 8 and caption provide a glimpse of the course integration of societal challenges. The designated textbook is Engineering Tomorrow [8]. The course is available over the worldwide web.

\section{DISTANCE EDUCATION DISSEMINATION (AND LOCAL INSTRUCTORS)}

At the education retreat, it was decided that distance education dissemination would be the expected delivery mechanism for each core course, and that elective courses would be identified (or developed) that used distance education methods. The core courses originate at UM. How could students at MSU, MTU, and industry be served well? It was decided that local instructors would be available at MSU and MTU for several purposes: provide face-to-face office hours, grade homework, administer and grade exams, and assign grades to students at that university. Each university was encouraged to obtain course approvals with course numbers at their university, and to assign credit hours consistent for their university; course approvals and local numbers were obtained at Michigan State University and Michigan Technological University. University term calendars are different. The student tuition payment is to his/her university, and there is no financial sharing of tuition funds. Costs to disseminate by distance education are borne by the originating university.

EECS 414 and EECS 830 use a high-quality high-cost dissemination of its course materials. Video is captured by a trained camera operator in a classroom studio with excellent lighting and sound capture facilities. The course materials and streaming video are posted to the class web site about one hour after the "live" class session. EECS 514 and 515 use a more costeffective dissemination process; video is captured by a WIMS staff operating a camera; the course materials and streaming video are posted to a university web site usually within a day after the "live" class session. Methods are being explored to port a laboratory based course (EECS 425).

\section{COURSE ENROLLMENTS}

Enrollment in each course has been consistently high. Except for the societal impact seminar course, each course is offered once per year, thereby necessitating a renewed student population each year. EECS 414 is a door-opener course, one that permits many students to get a glimpse of the MEMS and Microsystems area. Its enrollment numbers have ranged from 57 to 104 students at UM, plus about 50 students total at all USA distance education remote sites. The undergraduate-to-graduate student ratio is now about $2: 1$, different from the first years of the course that had a ratio about 1:2. EECS 425 is likewise a pseudodoor opener course, attractive because of its MEMS/Microsystems content and its ABET satisfying major design experience. EECS 425 enrollment is limited by laboratory space capability. Table 2 has enrollment history since the inception of the MEMS and Microsystems curriculum. For each course, two numbers are provided: the first number is the enrollment of local students at the originating university; the second number is the enrollment of distance education students (remote students, industry professionals, etc).

\begin{tabular}{|c|c|c|c|c|c|c|}
\hline Acad.Yr. $\rightarrow$ & $\begin{array}{l}2000- \\
2001\end{array}$ & $\begin{array}{l}2001- \\
2002\end{array}$ & $\begin{array}{l}2002- \\
2003\end{array}$ & $\begin{array}{l}2003- \\
2004 \\
\end{array}$ & $\begin{array}{c}2004- \\
2005 \\
\end{array}$ & $\begin{array}{l}2005- \\
2006 \\
\end{array}$ \\
\hline EECS 414 & & $\begin{array}{c}57+ \\
25\end{array}$ & $\begin{array}{c}66+ \\
23\end{array}$ & $\begin{array}{c}104+ \\
45\end{array}$ & $\begin{array}{c}77+ \\
50\end{array}$ & $\begin{array}{c}83+ \\
51\end{array}$ \\
\hline EECS 425 & $\begin{array}{l}13+ \\
\text { NA }\end{array}$ & $\begin{array}{c}26+ \\
16 \\
\end{array}$ & $\begin{array}{c}31+ \\
16 \\
\end{array}$ & $\begin{array}{c}42+ \\
7 \\
\end{array}$ & $\begin{array}{c}39+ \\
5 \\
\end{array}$ & $\begin{array}{c}48+ \\
13 \\
\end{array}$ \\
\hline EECS 514 & & & $\begin{array}{c}30+ \\
6 \\
\end{array}$ & $\begin{array}{c}16+ \\
6 \\
\end{array}$ & $\begin{array}{c}25+ \\
18 \\
\end{array}$ & $\begin{array}{c}29+ \\
13 \\
\end{array}$ \\
\hline EECS 515 & & & & $\begin{array}{c}17+ \\
2\end{array}$ & $\begin{array}{c}14+ \\
3\end{array}$ & $\begin{array}{c}10+ \\
4\end{array}$ \\
\hline EECS 830 & & & $\begin{array}{c}21+ \\
10 \\
\end{array}$ & & $\begin{array}{c}18+ \\
5 \\
\end{array}$ & \\
\hline \multicolumn{7}{|c|}{ LEGEND: } \\
\hline \multicolumn{7}{|c|}{ Enrollments are listed in format: UM + Distance Education } \\
\hline \multicolumn{7}{|c|}{ Bold numbers are first time course in MEMS/ systems curric'm } \\
\hline \multicolumn{7}{|c|}{$\begin{array}{l}\text { EECS } 425 \text { was an Integrated Circuits Lab 3-credits course until } \\
2001 \text {; it is now an Integrated systems Design } 4 \text {-credits course. }\end{array}$} \\
\hline
\end{tabular}

A table similar to Table 1 has been prepared for each core course, though not included in this paper for space considerations. The core courses have been received exceptionally well as evidenced by student course evaluation scores at UM; the rating scores for both course and teacher are among the best for undergraduate and graduate courses in the EECS Department at UM. Evaluations at MSU and MTU each use a different set of questions. Course evaluations by distance education students use yet another evaluation instrument. At UM, each undergraduate course has been mapped to a subset of 14 degree program outcomes (as done for ABET criteria). EECS 414 addresses 9 of the 14 program outcomes. Depending on the term, EECS 425 has addressed 10 or 11 of the 14 program outcomes. 


\section{MASTER OF ENGINEERING IN INTEGRATED MICROSYSTEMS DEGREE PROGRAM}

The development of the core curriculum also led to the establishment of a Master of Engineering (M.Eng.) degree in Integrated Microsystems. The degree program accommodates students and industry professionals with a wide variety of backgrounds in engineering, basic sciences, and industry manufacturing and management. The requirements of this program include the core courses, technical electives, breadth electives, and an industry-oriented team project. The technical electives include courses in fabrication technology, integrated circuits, RF MEMS and wireless communication, optical MEMS, microfluidics, bioMEMS, and environmental sensing. The breadth electives include manufacturing, management, quality engineering, financial analysis and other industry-relevant courses. The industry-oriented team project partners the student with a faculty member and industrial personnel in a project suggested by an industrial application. The team project is a very effective way to increase interactions and expose students to realworld applications and problems. Degree approval was secured at UM in 2002. MTU already had a generic Master of Engineering degree program. The M.Eng. degree can be completed by students taking coursework over the web.

\section{OTHER CONSIDERATIONS}

The significance of this curriculum development initiative includes numerous factors. First is a coordinated set of comprehensive MEMS and Microsystems courses and educational resources that are readily shared internationally. The course materials are generously shared, either as a delivered course via distance education, or as a transfer of course materials to faculty who decide to teach the course locally at their university. A second factor is the progressive educational and learning continuum for students with clearly identified links between the courses. Several renowned faculty contributed to development of the courses and course materials. Another factor was the tremendous cooperation and goodwill among faculty at the initial three-partner State of Michigan universities (MSU, MTU, UM).

Building upon the MEMS/Microsystems core courses curriculum, other new related courses that have been offered include Integrated Analog/Digital Interface Circuits (EECS 511), RF Wireless MEMS (EECS 598A), BioMEMS Through the Developing Organism (EECS 598B), and Micromanufacturing Processes (MTU MEEM 4640/5640). Also, the existence of the core courses has led to the inclusion of MEMS and microsystem topics in other courses as well, from sophomore year to the advanced graduate level.

At Michigan Tech, a course Micromanufacturing Processes (MTU MEEM 4640/5640) is a technical elective from a mechanical engineering perspective, developing a broader perspective to students in the program. Course topics include: Scaling analysis, micrometrology methods and instruments, precision measurements and practices, lithographic processes, diamond machining, micromilling, microdrilling, micro EDM (electrical discharge machining), and analytical modeling of processes and normal practices.

\section{SUMMARY}

The Engineering Research Center for Wireless Integrated MicroSystems (WIMS ERC) has developed five core courses (Figure 1) that provide a broad comprehensive curriculum in MEMS and microsystems. Upper-level undergraduate students, graduate students, and industry professionals from engineering (electrical, computer, mechanical, biomedical, chemical,

aerospace) and science (physics, chemistry, applied physics) have enrolled in the courses. Additional new technical and breadth elective courses have grown out of the core. Students are able to complete a master degree locally on campus or via distance education web online technology. Course enrollments have been consistently strong. Other universities, nationally and internationally, have used the courses in whole, or used course materials to further their own course offerings.

\section{ACKNOWLEDGEMENT}

The Engineering Research Centers Program of the National Science Foundation under Award Number EEC-9986866, wholly or partly, supports the WIMS Education program and projects.

\section{REFERENCES}

[1] Stephen D. Senturia, Microsystem Design, Kluwer Academic Publishers, 2000.

[2] Digest of Technical Papers, International Conference on Solid-State Sensors and Actuators (Transducers 'xx), 1985 through 2001.

[3] Digest of Technical Papers, Solid-State Sensor and Actuator Workshop, Hilton Head, South Carolina, Series 1984 through 2000 .

[4] Proceedings, IEEE International Micro Electro Mechanical Systems (MEMS) Conference, 1987 through 2006.

[5] S. Ballandras, M. Wilm, M. Gijs, A. Sayah, E. Andrey, J.-J. Boy, L. Robert, J.-C. Baudouy, W. Daniau, and V. Laude, "Periodic Arrays of Transducers Built Using Sand Blasting and Ultrasound Machining Techniques for the Fabrication of Piezo-Composite Materials," IEEE Ultrasonics Symposium, pp. 871-874, 2001.

[6] L. Spietz, K. W. Lehnert, I. Siddiqi, and R. J. Schoelkopf, "Primary Electronic Thermometry Using the Shot Noise of a Tunnel Junction," Science, v. 300, pp. 1929-1931, 20 June 2003.

[7] S. P. Woods, K. Lee, and J. Bryzek, "Overview of the IEEEP1451.2 Smart Transducer Interface Module," Analog Integrated Circuits and Signal Processing, 14(3), pp. 165177, November 1997.

[8] Engineering Tomorrow: Today's Technology Experts Envision the Next Century, Janie Fouke (Editor), T. E. Bell and D. Dooling (Writers), Institute of Electrical and Electronics Engineers, Inc, 2000.

\section{LIST OF ACRONYMS AND ABBREVIATIONS}

ABET

CMOS

Dis.Ed.Stds

$\mathrm{E} / \mathrm{D}$

EECS

ERC

LOCOS

MEMS

MSU

MTU

NSF

UM

US

WIMS
Accreditation Board for Engineering \& Technol'y Complementary-Symmetry Metal Oxide Semiconductor Process (see EECS 425)

Distance Education Students

Enhancement/Depletion Circuit Structure Electrical Engineering and Computer Science Engineering Research Center Local Oxidation of Silicon (see EECS 425)

Microelectromechanical Systems

Michigan State University

Michigan Technological University

National Science Foundation

University of Michigan

United States (see Table 1)

Wireless Integrated MicroSystems 